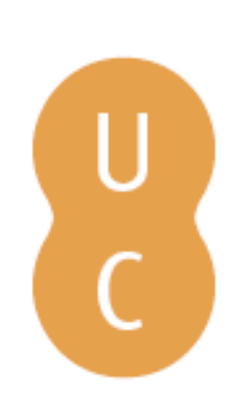

\title{
nombalina
}

\section{Maintenance strategies to reduce downtime due to machine positional errors}

Autor(es): $\quad$ Shagluf, Abubaker; Longstaff, A. P.; Fletcher, S.

Imprensa da Universidade de Coimbra; Faculdade de Ciências e

Publicado por: Tecnologia da Universidade de Coimbra, Departamento de Engenharia Mecânica

URL persistente:

URI:http://hdl.handle.net/10316.2/33327

DOI:

DOI:http://dx.doi.org/10.14195/978-972-8954-42-0_16

Accessed : $\quad$ 26-Apr-2023 14:50:42

A navegação consulta e descarregamento dos títulos inseridos nas Bibliotecas Digitais UC Digitalis, UC Pombalina e UC Impactum, pressupõem a aceitação plena e sem reservas dos Termos e Condições de Uso destas Bibliotecas Digitais, disponíveis em https://digitalis.uc.pt/pt-pt/termos.

Conforme exposto nos referidos Termos e Condições de Uso, o descarregamento de títulos de acesso restrito requer uma licença válida de autorização devendo o utilizador aceder ao(s) documento(s) a partir de um endereço de IP da instituição detentora da supramencionada licença.

Ao utilizador é apenas permitido o descarregamento para uso pessoal, pelo que o emprego do(s) título(s) descarregado(s) para outro fim, designadamente comercial, carece de autorização do respetivo autor ou editor da obra.

Na medida em que todas as obras da UC Digitalis se encontram protegidas pelo Código do Direito de Autor e Direitos Conexos e demais legislação aplicável, toda a cópia, parcial ou total, deste documento, nos casos em que é legalmente admitida, deverá conter ou fazer-se acompanhar por este aviso.

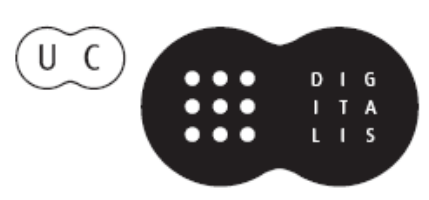




\title{
Maintenance Strategies to Reduce Downtime Due to Machine Positional Errors
}

\author{
Abubaker Shagluf; A. P. Longstaff; S. Fletcher \\ abubaker.shagluf@hud.ac.uk; a.p.longstaff@hud.ac.uk; s.fletcher@hud.ac.uk \\ Centre for Precision Technologies, University of Huddersfield \\ Huddersfield, United Kingdom
}

\begin{abstract}
Manufacturing strives to reduce waste and increase Overall Equipment Effectiveness (OEE). When managing machine tool maintenance a manufacturer must apply an appropriate decision technique in order to reveal hidden costs associated with production losses, reduce equipment downtime competently and similarly identify the machines' performance.
\end{abstract}

Total productive maintenance (TPM) is a maintenance program that involves concepts for maintaining plant and equipment effectively. OEE is a powerful metric of manufacturing performance incorporating measures of the utilisation, yield and efficiency of a given process, machine or manufacturing line. It supports TPM initiatives by accurately tracking progress towards achieving "perfect production."

This paper presents a review of maintenance management methodologies and their application to positional error calibration decision-making. The purpose of this review is to evaluate the contribution of maintenance strategies, in particular TPM, towards improving manufacturing performance, and how they could be applied to reduce downtime due to inaccuracy of the machine. This is to find a balance between predictive calibration, on-machine checking and lost production due to inaccuracy.

This work redefines the role of maintenance management techniques and develops a framework to support the process of implementing a predictive calibration program as a prime method to supporting the change of philosophy for machine tool calibration decision making.

Keywords-maintenance strategies, down time, OEE, TPM, decision making, predictive calibration.

\section{INTRODUCTION}

Effective maintenance management is critical to the operation of the machines. Taking into consideration various concepts of programs, managers may plan and undertake maintenance activities proactively or reactively. A reactive approach initiates maintenance activities after some failure or problem occurs. This approach is typical for traditional manufacturing organisations where maximum throughput is the highest priority or where there is low investment in reconfiguring manufacturing systems. Due to growing pressure on manufacturing companies for improvements on productivity industrial companies' maintenance managers take preventive measures before crises occur in order to maintain machine tool availability. In general maintenance terms, this means ensuring that production continues to run. With respect to the positional accuracy of the machines, tighter tolerance demands from customers, means that maintaining the quality performance of individual machine tools is essential to avoid expensive rework or scrap, with the detrimental impact this has on rate of product output. As the name implies, a proactive maintenance approach uses well-defined preventive measures to prevent failures and shutdowns.

This paper is oriented towards predictive calibration as a proactive approach for eliminating production failure due to machine tool inaccuracy. The problem of the decision-making process is discussed, leading to the importance of making distinctions between reaction to incidents and the need for onmachine checking and preventive and predictive calibration.

The article presents various maintenance management approaches and how these can be applied to achieve competitive advantage by reducing machine tool downtime. It explores, by means of a review, which maintenance management strategies are used and how they are selected. It refers to the authors' previous work $[1,2]$ which proposed a model to help selection of the most cost effective machine tool measurement policy, and how to improve the effectiveness of calibration decision-making. Finally, this paper discusses how to assess the impact of the management strategies on the strategic objective of maintaining positional accuracy without prohibitive impact upon machine availability.

\section{MANAGEMENT OF INDUSTRIAL MAINTENANCE}

Over recent years, maintenance management has changed, possibly more than any other management discipline [3]. The change is a response to increasing competition and higher value demands on manufacturing output. It also includes the growing awareness of the influence of machine breakdown on safety and the environment [3].

Manufacturing development needs to be supported by effective and efficient maintenance. The maintenance function has become more complex, involving technical and management skills and requiring the flexibility to cope within a dynamic business environment. Emphasis should be made on carefully implementing a well-considered maintenance strategy, since simply following the latest trends can lead to significant negative impact in terms of wasted of time, money and morale. The purpose of maintenance management is to reduce the adverse effects of breakdown and to maximise the production system availability at minimum cost [4]. With the 
increasing complexity of modern $\mathrm{CNC}$ machine tools, the correct maintenance policy is ever more critical to the ability of the manufacturing organisations to compete. In this respect, operations management, especially maintenance management, is taking on a wider organisational strategic role [5].

Total maintenance costs for different machine tools or production lines will vary, depending upon the type of work, complexity of the machine and age of the machine, etc. It is therefore critical to evaluate each machine individually as well as the holistic viewpoint to establish an appropriate maintenance policy for each machine and production line. It is important not to perform excessive maintenance activities [4]. As reported by Mather, there still remain many opportunities to bridge the gap between the philosophy and practical application of these strategies [6].

Maintenance management approaches have been studied and presented by different authors with varying perspective. In this paper, maintenance management methodologies and their application are redefined and discussed with respect to decision making for planning calibration of positional errors; the eventual aim is to develop a framework to support the process of implementing a predictive calibration program as a prime method for supporting a change of philosophy for machine tool positional accuracy maintenance.

There are three basic maintenance strategies: Corrective (Run-to failure) unplanned; preventative (time-based); and predictive (condition-based). Predictive Maintenance (PdM) is a strategy that includes feedback of the instantaneous condition of the machine and detects degradation before a fault becomes critical [7].

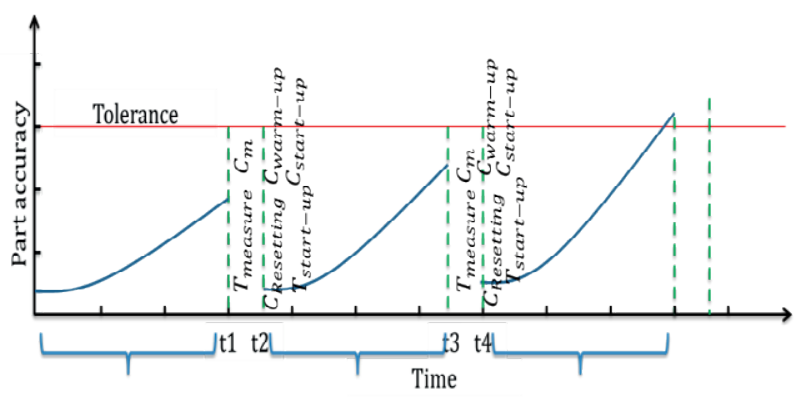

Fig. 1. Preventative calibration and adjustment at fixed rate

In recent years, the tools to enable comprehensive measurement of machine tool accuracy have become more readily available. For this reason, management strategies of preventative calibration and machine tool diagnostic techniques have attracted considerable attention. This approach uses modern metrology and analysis techniques to identify and predict the signs of deterioration or imminent failure. Fig. 1 shows such a time-based schema, where regular measurement and remedial work or compensation can be used to keep the machine within the desired accuracy tolerance. Naturally, it is important that the time between calibration cycles is no longer than the time taken for the machine to exceed the tolerance. A drawback of this strategy is the length of time required to perform the calibration. On large or complex machines, a full calibration can take several days.

Predictive Calibration ( $\mathrm{PdC})$ is a new methodology proposed to be analogous with, or indeed a subset of, a PdM strategy. Correctly implemented, it can achieve the same goal of sustaining the machine accuracy, but reduce the unnecessary downtime required for period calibration. It is intended to be a formalised approach applied to machine tools to measure and monitor any degradation in the mechanical parts to assist with maintaining the key performance indicator (KPI) of positioning accuracy, while having the added-value of revealing other maintenance issues such as wear in ball-screws, guide-ways, impending bearing failure, etc. Degradation of the machine condition over time can be extracted by analysis of the historic data from the machine. Such an inspection history may be provided by "quick check" tools such as artefact probing, double Ballbar or any other appropriate measurement technique. Such measurements take between a few minutes and an hour to run. Downtime cost must be traded-off against richness of data and required trending of daily perturbations in performance.

This can be achieved by establishing relevant secondary KPI's associated with the measurement method that indicate degradation in overall machine accuracy performance. Setting appropriate tolerances then provides a trigger from these checks to instigate further intervention. Unambiguous analysis of the data is the basis of decision making for the machine to be corrected [7].

Although inspired by PdM, accuracy is difficult to monitor "live" with available technology so a periodic approach is required. It is therefore essential to apply the necessary technical knowledge along with management strategies and decision making skills [1]. Fig. 2 shows the periodic cycle of intermittent "quick checks" which eventually lead to a requirement (at time $=\mathrm{t} 5$ ) for more in-depth analysis through a full accuracy calibration.

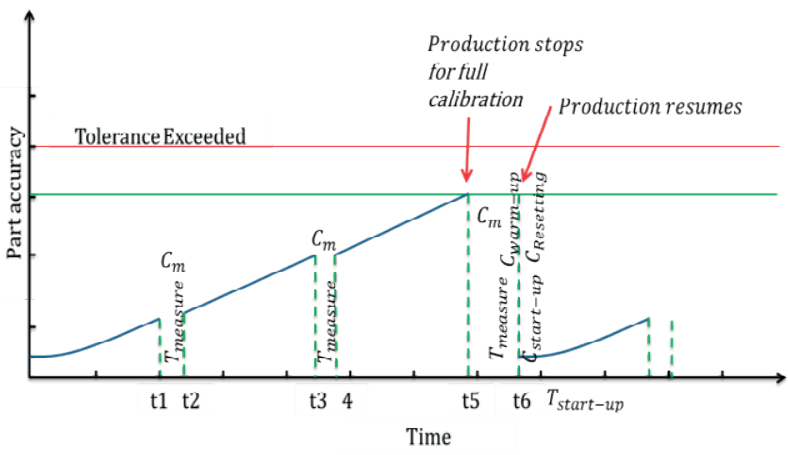

Fig. 2. Predictive calibration

Quality has always been one of the most important factors for achieving competitive advantage [8]. As a result, quality management theory is increasingly adopted in industry for 
improving competiveness and financial results. Total quality management (TQM) has been one of the most dominant methods for several years. Its goal is continuously improving organisations' abilities to deliver high quality products and services to customers, thus meeting their requirements [9]. The evolution of other quality management methods like Lean Enterprise and Six Sigma; have given the manufacturing industry the options for selecting the most suitable strategy to meet their needs. Consequently, the right balance between each of these philosophies, allowing more flexibility to the users and their integration, continues to grow towards improving overall performance [10].

In some cases, Six Sigma could be the most appropriate backbone for maintenance management improvement and the deliverance of better organisation/machine performance and cost reduction. It seeks to eliminate all unnecessary steps from a company's the processes. Six Sigma provides a structured approach to solving problems through the implementation of five phases; Define, Measure, Analyse, Improve and Control (DMAIC). Six Sigma has been described one of the WorldClass processes, [11], meaning that it can be an optimal framework for the maintenance process. This assumes that it is comprehensive and understandable for all contributors in the process, and requires minimal implementation costs. It also implies that it is globally applicable and increases overall equipment effectiveness (OEE) of the technical systems, which ultimately leads to a greater profit for the business [11].

Applying Six Sigma to maintenance follows a standard method for a program: focus on the process and engage workers. Engaging the people who best understand the process includes both the maintenance personnel and the shop-floor operators. Operators who run the machines are a key resource for achieving higher machine uptime and overall effectiveness. It is commonly assumed that such preventive management techniques work better in large companies, especially those engaged in mass production [12]. The philosophy is more difficult to apply in small companies where the investment cost of implementation is difficult to justify, even though it might eventually lead to a reduction in lost revenues and overall downtime costs.

\section{TPM}

One approach to improving the maintenance activity performance is to implement the total productive maintenance (TPM) philosophy. Based on his own observations, Nakajima [13]developed the original approach of total productive maintenance (TPM) and introduced it in Japan in 1971.

A substantial amount of literature is available from various resources on the discussion of TPM (McCall [14]; Wang [15, 16]; McKone [17]; Ahuja and Khamba [18]; etc.). However, the available literature does not explicitly discuss the positional accuracy of the machine tool. There is also a large body of literature on the role of maintenance in measuring and improving maintenance performance. Some key review articles such as: Lofsten [4]; Garg [19]; Parida [20, 21]; Al-Najjar [22]; Alsyouf [23]; Al-Turki [24]; and Simoes [5].
Academics and industry experts have published articles and case studies to raise the profile of this methodology. Consequently, TPM has expanded greatly across the world [19]. According to Pedja and Rall, "One of the concepts which cannot be avoided in reaching World-Class maintenance in a company is the application of Total Productive Maintenance" [11]. While this statement can be challenged since it makes TPM an imperative rather than an option for success, it highlights the case for taking an holistic view of the management of a company's resources.

TPM is an approach that organises all employees from top management to shop-floor workers. Nakajima argues that, "In discussing quality control, people often say that quality depends on process. Now, with increasing robotisation and automation it might be more appropriate to say that quality depends on equipment." [13]. While this is true for highly automated industries, there remains a large proportion of manufacturing industry that relies on manually-serviced or semi-automatic production. Nevertheless, modern CNC machine tools are being given greater complexity that needs to be considered in this context.

The following five critical success elements have been defined for delivering benefits from TPM:

- Maximise equipment effectiveness.

- Establish a thorough system of preventative maintenance for the equipment's entire life span.

- Involve all departments (engineering, operations, and maintenance).

- Involve all employees from top management to workers on shop-floor.

- Promote TPM through motivation management: autonomous small group activities.

These concepts can all be translated to the challenge of maintaining machine tool positional accuracy. There are many examples of TPM effectiveness [12] such as reduction of equipment breakdown of $2 \%$, up to $26 \%$ increase in equipment operation rates, $90 \%$ reduction in process defects and $40-50 \%$ increase in labour productivity [13]. However, it has been reported to take an average of three years from the introduction of TPM to achieve such dramatic results. Some companies fail to reach this stage because they do not support the entire workforce or involve all levels of management [13]. These initiatives failed because they were applied piecemeal and so were rejected by those people who did not have ownership of the integration [12]. Restoring the equipment to its proper condition and educating workers about the equipment are therefore fundamental costs that the company should take into account.

\section{STRIVING FOR OEE - OVERALL EQUIPMENT EFFECTIVENESS}

Setting understandable and quantifiable targets is a fundamental strategy for ensuring that all elements of the workforce can focus on a common goal. Key performance 
indicators (KPIs) are measurable metrics that provide an essential common reference for comparison of achievement against target. The value placed upon a KPI must be sufficiently ambitious to drive change, but must be realistic or will lead to failure and constant "firefighting."

A particular issue around machine tool accuracy is the existence of possibly conflicting KPIs. For example, when a machine is required to produce low volumes of products then the KPI for machine utilization might be low. This would allow plenty of time to carry out measurement tasks to ensure that accuracy levels were maintained at a high value. The converse is true; where high production rates are demanded, then this can affect the ability to meet accuracy maintenance targets. This problem is exacerbated where two independent departments have "ownership" of the conflicting KPIs; the maintenance department is required to ensure accuracy, while the production department is measured against production rate. This is why the company-wide approach is so important.

The result of TPM activities is made evident by measuring the Overall Equipment Effectiveness (OEE). Nakajima [13] identified the input factors as man, machine and material and the outputs comprised of production $(\mathrm{P})$, quality $(\mathrm{Q})$, cost $(\mathrm{C})$, delivery (D), safety, health and environment (S), and morale (M). TPM strives to improve OEE by maximising output while minimising input, i.e. the Life Cycle Cost [13]. More clearly, TPM strives to maximise (PQCDSM) by maintaining ideal operation conditions and running equipment effectively. A machine, equipment or instrument that often breaks down, experiences speed losses, produced rejects or non-conformance parts is not operating effectively.

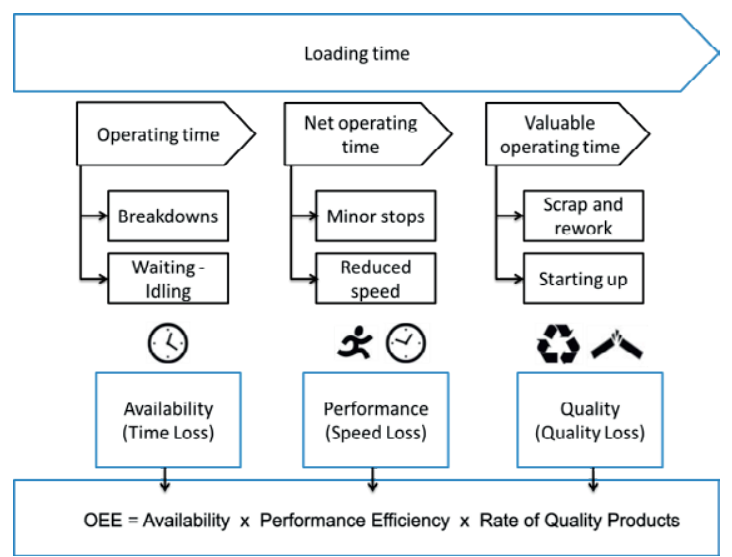

Fig. 3. Overall Equipment Effectiveness

To achieve OEE, TPM focuses on eliminating the six major equipment loss elements "six big losses" $[12,13]$, which are categorized in Fig. 3.: breakdown due to equipment failures; setup and unnecessary adjustments; idling and minor stops; reduced speed; start-up rejects; and production rejects.

The final two "losses" are the quality related waste which can partly derive from the positional inaccuracy of the machine. Once again, a balance must be achieved between addressing these issues and the negative impact that the proactive tasks will have on downtime of the machine. A further conflict, which cannot be ignored, is that maximizing speed of production can have an adverse effect upon the accuracy of the machine.

Calibrating the machine regularly has a time penalty, but aims to produce better overall machine availability by reducing scrap and rework. Therefore, it will increase the effective operating time by eliminating the wasteful bad-production time. The machine availability will have a great influence on having better performance efficiency and as a result a higher quality rate of parts will be produced. In other words, maintaining the machine regularly should increase the OEE.

\section{The EIGHT PILlaRs OF TPM}

The Japan Institute of Plant Maintenance (JIPM) developed an eight pillar approach to TPM, as shown in Fig. 4 that is focused on achieving:

- Zero Accidents

- Zero Break-downs

- Zero Defects

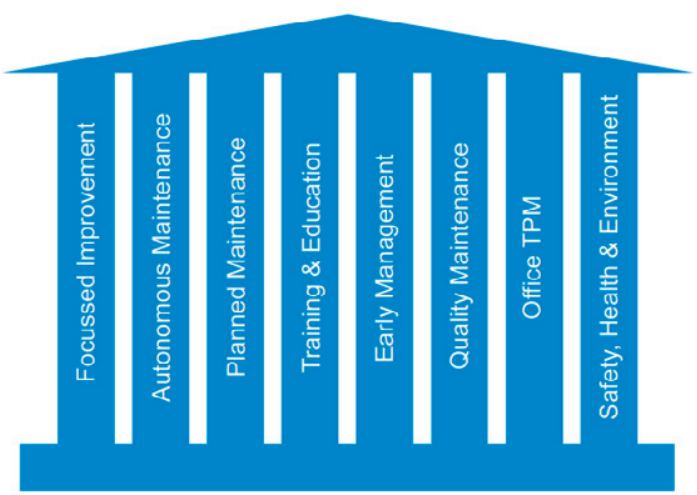

Fig. 4. Eight pillar approach to TPM (source:[25])

The goal for each pillar is to reduce loss with the ultimate aim of elimination of all losses. The overall process is a long term structure to support the cultural change within the industry. These pillars form an organised structure that bridges the gap in a way of managing change to ensure the industry sustains improved results for the future. The way in which these pillars are applied to machine tool calibration is detailed below.

\section{A. Focusssed Improvement}

The first pillar of TPM is focused improvement, which is based on the belief that, "it can always be better." In order for an industry to maintain maximal efficiency and availability of all its machines, it needs a different approach from the traditional concept of maintenance management. This must 
take into account the entire organization as a man-machineenvironment. It must also apply continual measures to prevent all losses, while improving maintenance processes.

This pillar provides a structured, team-based approach in order to eliminate losses in any process [25].

The focused improvement pillar can reduce defects and machine inaccuracy by developing the capabilities of teams to be self-sufficient in applying appropriate problem solving, as well as improving safety performance through to eliminating losses. It also ensures that the approach taken is repeatable and consistent, to assure sustainability [25].

\section{B. Autonomous Maintenance}

The second of the eight pillars of TPM is autonomous maintenance. This pillar aims to increase the skill levels of maintenance personnel so they can better understand, manage and improve their machines and the production process. The objective is to change workers from being reactive to working in a more proactive way [25], to achieve optimal conditions that eliminate stops as well as reducing the production of nonconformance parts, rejects and machine failures.

For instance, a CNC machine tool operator might traditionally react to inaccuracies in a part by making minor adjustment to the machine's set up or an offset in the part program. It is also quite common for an operator to "override" a feed-rate to increase production rates, or override a spindle speed command if the machining process "sounds" wrong. However, such a course of action, when taken in isolation, can have serious ramifications. Although a change in procedure can benefit a particular job, it could make some other jobs worse, or at least could mask an underlying problem. These undocumented reactive measures should be eliminated as part of autonomous maintenance. Instead, the knowledge and experience of the operator should be embraced to inform the maintenance department of potential issues developing on the machine.

\section{Planned maintenance}

The third pillar of TPM is planned maintenance. It provides a structure that follows an approach to establish clear maintenance plans that improves the machine reliability at optimum cost. A highly skilled maintenance team leads the planned maintenance activities and they should be able to provide a clear evaluation of the current maintenance performance and costs to set the focus for the pillar activity [25]. Both autonomous and planned maintenance go hand in hand together to support each other to establish a sustainable standard basic condition and the team focuses on eliminating the causes of the machine positional errors, machine deterioration or imminent failure. The maintenance team identifies the optimum strategy for maintaining the machine, starting with a preventative (Time-based) maintenance strategy then introducing predictive maintenance where appropriate [25].

\section{Training and education}

Training and educating workers is essential in order to change the culture of the company. Good education will alter the way the workers react when changes are proposed. For example, the knowledge and skills of maintenance technicians may be useful to further improve the detail of the maintenance plan [19]. However, this wealth of experience can only be exploited if all parties communicate with a common language and reference frame. This pillar ensures that employees are trained in the skills identified as necessary both for their personal development and for the effective deployment of TPM; without sufficient education, the impact of the other pillars will not be sustainable [25].

Machine tool accuracy is affected by a complex interaction of many factors. Therefore, education in the fundamentals of the issue and training in specific maintenance tasks must precede implementation of changes to maintenance procedures. The maintenance technicians should be given full training in order to eliminate any misinterpreting, false readings and therefore false reaction. Machine operators should be suitably informed of the reasons that maintenance technicians are performing measurement jobs on their machines so that they can provide support evidence for any root cause analysis. Product designers need to understand the true capability of machines so that they can tailor their designs according to available assets, or else specify that new equipment is required to meet their exacting demands.

\section{E. Quality Maintenance}

This pillar stresses that everyone is responsible for maintaining optimal quality conditions and striving for zero defects. Operators and maintenance workers must have the essential capability to sustain the quality of machine conditions so that they can rectify any machine deterioration and eliminate any process problems.

Critical to the success of maintaining machine tool accuracy is the need for the measurement action to be done properly. Measurement tools must be kept protected, clean and tidy to a level that is not always seen with other maintenance tools. For example, some maintenance workers keep dial/digital test indicators, able to measure with ten micron resolution, unprotected in their tool boxes alongside spanners and screw drivers. In this situation, without proper use and storage, no subsequent measurement could be relied upon.

\section{F. Office TPM}

Office TPM is a very important pillar that concentrates on all areas that provide administrative and support functions in the whole industry. This plays an important role in scheduling measurement tasks, collating and safely storing data, etc. This function allows a single measurement to become part of a company-wide investigation, maximising the value of the measurement time. 


\section{G. Safety, Health and Environment}

Safety, health and the environment pillar aims to eliminate the root of causes of incidents and reduce the risk of future potential incidents. It targets workers' behaviour, machine conditions and the management system. It can prevent the recurrence of lost time incidents and reduce the number of minor incidents. The benefit of this is a financial saving in the cost of investigation and compensation as well as reputational impact [25].

Recent trends in distributing the measurement tasks for machine quick checks have led to higher requirement for health and safety. For instance, the double ball bar is a tool that can be used by machine tool operators, but which traditionally required that the machine doors be open to allow the data capture wire to be connected to a PC. In recent years, Renishaw plc developed a wireless version of the device (QC$20 \mathrm{w}$ ) so that it can be operated without the need for safety doors to be open.

Presently, more complicated measurements using, for example, a laser interferometer are more difficult to be achieved with the machine doors closed. They are run under special maintenance modes by expert personnel. However, this could be improved by modifying the machine tool to allow access for the laser without interfering with the safety systems.

\section{PRedictive Calibration ScEnario}

A strong case is required to justify the period of downtime for machine tool calibration if the machine is producing the quantity of parts desired within their nominal tolerance. A new method for maintaining machine tool accuracy that is complimentary to the predictive maintenance paradigm is required. This strategy, called predictive calibration, is a methodology that depends on the prediction of the degradation in machine tool accuracy based upon regular data capture. It is shown in Fig. 5.

Predictive calibration is a methodology that depends on the prediction of the degradation in machine tool accuracy based upon regular data capture. It is a new method of identifying indirect boundaries of machine tool working tolerance. These boundaries reflect the degradation level corresponding to production capacities and the resultant effect on the quality of the part produced. Although introducing such a strategy will introduce a new cost, the aim is to offset this investment by optimising the operational efficiency and reducing the overall downtime cost due to unexpected and unplanned quality issues of the machine. The further benefit is that, being in control of the machine accuracy, it will reduce the overall downtime of a manufacturing facility by being able to eliminate the machine as a root cause of any failure later in the production process.

The main objective is achieved by monitoring the condition of the machine tool by collecting data using quick check measurement techniques or monitoring post-process quality data. Calibration should, therefore, be driven by the data measured from either the machine or the part. Building a database of inspection history by measuring the machine on a regular basis, with relatively non-invasive methods, will make the decision of scheduling extensive calibration a better informed process [1].

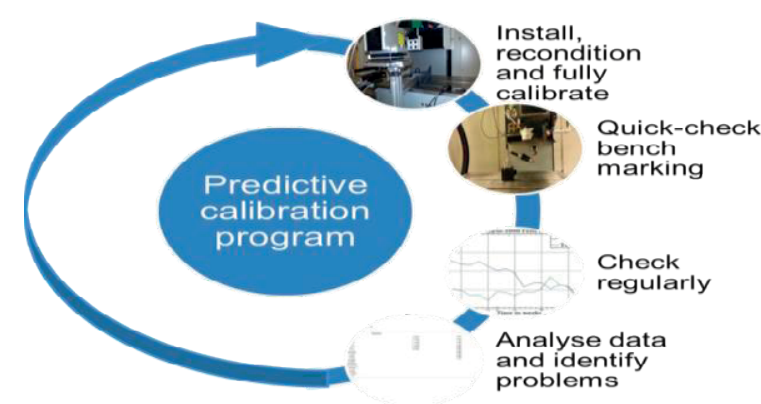

Fig. 5. Predictive calibration process

\section{Maintenance Strategy As Part Of An Holistic PROCESS}

Statistical data describing the frequency of failures can be summarised in what is called a "bathtub curve." illustrated in Fig. 6. The bathtub curve is a well-known theoretical representation of the mean-time-to-failure (MTTF) profile over a product lifecycle. It indicates that a new product (in this case machine tool) has a high likelihood of failure due to design errors and/or installation problems throughout the first few weeks of operation. These failures are referred to as "wear in" failures [26]. After this initial period, the likelihood of failure is relatively low for a relatively extended period of operation. This period of low risk of failure is known as the "normal wear" period that represents most of the life of the machine tool. After this normal period, the machine gradually reaches the end of its designed life and the chance of failure increases with time. This is called "wear-out" failures [26, 27].

Preventative and predictive maintenance (accuracy-based), consists of deciding whether or not to maintain a system according to its state [19]. They are effective proactive counter measures for machine failures. However, there are some machine early design errors and other accidental errors caused primarily by operation errors. All these could be reduced efficiently by the implementation of TPM. The success of TPM in this case depends on the cooperation of all departments by ensuring that the installation, wearing-in and service life of the machine are managed to limit breakdowns and accuracy failures.

The bathtub curve drawn to represent any particular machine tool is dependent upon a number of factors including: how many other machines of that type have been produced by the original equipment manufacturer (OEM); how many have been used by the end-user of the system; what variance there is in production types; complexity of the machine; age of the facility; etc.

Often, the performance, repeatability and precision designed into machine tools is assumed to be guaranteed from the OEM facility to the end-user's factory. However, this is not 
always the case. Furthermore, proper installation, in a manner designed specifically to meet the machine's requirements, is essential to minimize the wear-in accuracy failures. An important aspect is the foundation and subsoil onto which the machine is installed. It is an essential aspect of attaining optimal performance with the machine tools, but is often not considered as a measurable property of the machine. Nevertheless, there are many cases where the main cause for excessive maintenance or scrap at an early stage of the machine's life was due to unmonitored settling of the foundations. Normal accuracy wear also derives from an installation that did not provide satisfactory support or isolation against shock and vibration [28].

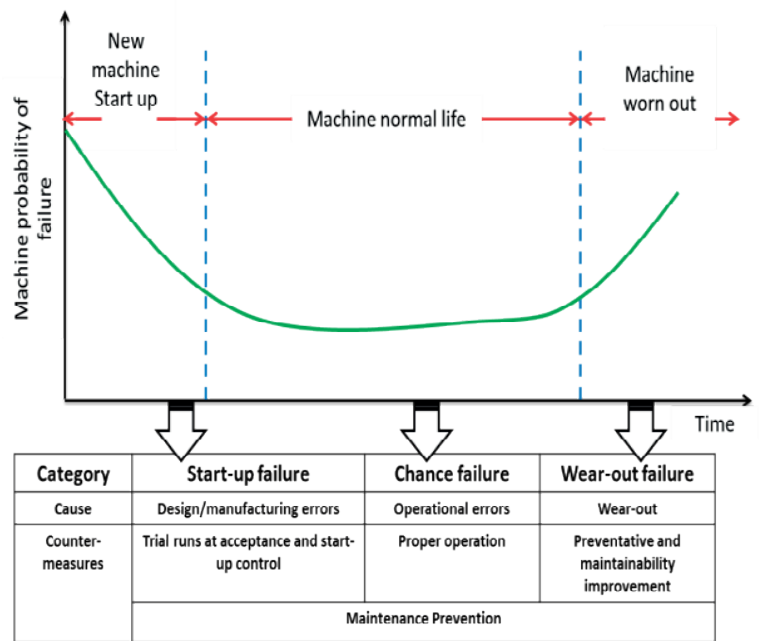

Fig. 6. Typical bathtub curve and machine failure counter measures [13]

Other factors that could affect the early part of the machine's working life include the unexpected effects from nearby manufacturing operations including heavy presses, moving cranes, local transport infrastructure, etc. Not every machine is affected by such perturbations, but without comprehensive accuracy monitoring, a new machine can produce unexpectedly poor performance due to such effects.

Early-life incidents occur dynamically and unpredictably while the machine is being integrated into the production processes. Programming/operator errors due to unfamiliarity can increase the likelihood of collisions. Such events makes the new machine tool have a high likelihood of sudden accuracy change throughout the first few weeks of machine operation and cause operation problems that interrupt the production process introduce delays in the working schedule plan. For instance, a collision problem could damage the machine guideways or the ball-screw. Consequently, the accuracy of the machine tool deviates resulting in manufacturing error. Reactive maintenance would not see this error until after it had occurred. Worse still, since the machine is only being "learned" by the company, it is likely that root cause analysis will focus on other aspects of the production loop, such as programming or fixturing, rather than the new machine. Therefore, this is one of the most critical periods of the machine lifecycle to have a good understanding of the machine accuracy KPI. Benchmarking the machine at the point of installation (or preferably the point of assembly, which might be at the OEM's facility) is an essential factor to enabling the new predictive calibration strategy to handle out-of-ordinary events.

These early problems could be mitigated through designers and operators experience. When installing a similar machine on subsequent occasions, the initial phase of the machine's life should be less arduous.

One of the main contributing factors to the cost of a calibration is the downtime of the machine tool, which is often perceived to be a barrier to implementing predictive calibration [2]. Both economic and performance aspects need to be considered in order to make a decision in support of machine checking and particular positional error handling policies [1]. Financial reductions can be achieved when using preventative and predictive calibration in collaboration with TPM. Such techniques are intended to leading to a better maintenance activity performance that can provide benefits to different volumes and value of manufacturing productivity [2].

\section{Discussion AND CONCLUSION}

Maintenance is a strategic concern in high value manufacturing. To achieve an optimal, cost-effective maintenance approach, the analysis of failures and development and use of applicable mathematical cost algorithms is essential. The performance of a machine tool or group of machine tools depends not only on the design, layout and operation, but also on effective calibration and maintenance of the machines during their operational lifetime.

Advanced manufacturing technologies and modern metrology introduces key factors such as downtime and product quality when measuring maintenance effectiveness. Considerations of safety and environmental sustainability of manufacturing facilities have also become increasingly important. Waste in manufacturing, scrapped raw materials, energy and consumables during re-machining all have a significant cost and negative impact on the environment.

Product inaccuracy can be derived from many factors. One of these is the machine tool on which the part is produced. Errors in the machine can also be caused by many factors. These can be worst during the early life of the machine. Design, installation and operation problems, poor measuring techniques, poor measuring equipment and misinterpretation of measuring data could lead to machine inaccuracy or incorrectly ascribing product inaccuracy to the machine. A scientific approach to measurement is essential for minimising uncertainties and aiming for better decision making.

Performance, repeatability, and precision designed into today's sophisticated machine tools cannot be delivered without proper installation in a manner designed specifically to meet the machine's requirements. Predictive calibration is a technique which helps to facilitate greater control of manufacturing accuracy issues and diagnosis of the cause of out of tolerance parts. In turn, this leads to a reduction in 
machine tool downtime and facilitates traceable inspection on the machine, increasing overall efficiency.

Defining KPI's is a common management tool. Performance metrics provide an essential common platform for comparison, based on which improvements can be sought for any individual indicator. Performance metrics assist in establishing benchmarks that provide guidance to management in decision-making and indicate the success of current facility management practices. Furthermore, authentic, well-defined, and compatible performance indicators should be the backbone of strategies for analysis and decision-making.

It has been accepted over the last sixty years that the total productive maintenance management technique saves a significant amount of money in lost production, reduces waste production and can extend machine lifetime.

The article presented review of maintenance management methodologies, in particular TPM, and their application to positional error calibration decision-making. This paper is oriented to predictive calibration as a proactive approach to addressing machine tool inaccuracy and the problem of the decision making process and therefore the importance to make distinction between incidents and the need for on machine checking, preventive and predictive calibration. This work seeks to redefines the role of maintenance management methods and develops a framework to support the process of implementing a predictive calibration program as a prime method to supporting the change of philosophy for machine tool calibration decision making. This paper discusses some examples of the different TPM pillars for the problem of machine tool position accuracy maintenance.

\section{ACKNOWLEDGMENT}

The authors gratefully acknowledge the UK's Engineering and Physical Sciences Research Council (EPSRC) funding of the EPSRC Centre for Innovative Manufacturing in Advanced Metrology (Grant Ref: EP/I033424/1).

\section{REFERENCES}

[1] A. Shagluf, A. P., Longstaff, S., Fletcher, P., Denton, , "Toward a Downtime Cost Function to Optimise Machine Tool Calibration Schedules," presented at the International Conference on Advanced Manufacturing Engineering and Technologies, KTH Royal Institute of Technology in Stockholm, Sweden, 2013. A. Shagluf, S., Parkinson, A. P., Longstaff, S., Fletcher, , "Towards an Optimization Calculation for Preventative and Reactive Calibration Strategies," presented at the Sustainable Design and Manufacturing 2014, SDM-14., Cardiff, Wales, UK. 2014.

[3] J. Moubray, Reliability-centred maintenance. New York, N.Y: Industrial Press, 1992.

[4] H. Löfsten, "Measuring maintenance performance - in search for a maintenance productivity index," International Journal of Production Economics, vol. 63, pp. 47-58, 2000. of maintenance performance measurement: A conceptual framework and directions for future research," Journal of Quality in Maintenance Engineering, vol. 17, pp. 116-137, 2011.

\& Francis, 2013

A. Shagluf, A. P., Longstaff, S., Fletcher, P., Denton, A., Myers, , "Predictive Calibration-Based Tolerance Boundaries For Arresting Deterioration of Machine Tool Accuracy," presented at the Manufacturing the Future conference 2013, Manufacturing at Cranfield University, 2013.

[8] V. B. Andrea Ionica, Eduard Edelhauser, Sabina Irimie, "TQM and Business Excellence.pdf," Annals of the University of Petrosani, Economics, vol. 10(4), pp. 125-134, 2010.

[9] J. S. Oakland, Total Quality Management, Second ed. Oxford: Butterworth-Heinemann, 1993.

[10] B. Klefsjo and B. Bergquist, "Six Sigma and Total Quality Management Different Day Same Soup," Inernationa Journal for Six Sigma and competitive Advantage, pp. 162-178.

[11] M. Pedja and Klaus Rall, "Six Sigma concept in the maintenance process of technical systems," Mechanical Engineering, vol. 3, pp. 93-108, 2005.

[12] D. McCarthy and N. Rich, Lean TPM: a blueprint for change. Amsterdam; London: Elsevier Butterworth-Heinemann, 2004.

[13] S. Nakajima, Introduction to TPM: total productive maintenance. Cambridge, Mass: Productivity Press, 1988.

[14] J. J. McCall, "Maintenance Policies For Stochastically failing Equipment: A Survey," Management Science, vol. 11, pp. 493$524,1965$.

[15] C. Wang and B. Thomas, "Predictive maintenance and machine tool calibration techniques," vol. 69, ed. Cincinnati: Gardner Business Media Inc, 1997, p. 102.

[16] H. Wang, "A survey of maintenance policies of deteriorating systems," European Journal of Operational Research, vol. 139, pp. 469-489, 2002.

[17] K. E. McKone and R. G. Schroeder, Cua, Kristy O., "The impact of total productive maintenance practices on manufacturing performance," Journal of Operations Management, vol. 19, pp. 39$58,2001$.

[18] I. P. S. Ahuja and J. S. Khamba, "Total productive maintenance: literature review and directions," International Journal of Quality \& Reliability Management, vol. 25, pp. 709-756, 2008.

[19] A. Garg and S. G. Deshmukh, "Maintenance management: literature review and directions," Journal of Quality in Maintenance Engineering, vol. 12, pp. 205-238, 2006.

[20] A. Parida and U. Kumar, "Maintenance performance measurement (MPM): issues and challenges," Journal of Quality in Maintenance Engineering, vol. 12,pp. 239-251, 2006.

[21] A. Parida and G. Chattopadhyay, "Development of a multi-criteria hierarchical framework for maintenance performance measurement (MPM)," Journal of Quality in Maintenance Engineering, vol. 13, pp. 241-258, 2007.

[22] B. Al-Naijar, "The lack of maintenance and not maintenance which costs: A model to describe and quantify the impact of vibrationbased maintenance on company's business," International Journal of Production Economics, vol. 107, pp. 260-273, 2007.

[23] I. Alsyouf, et al., "The role of maintenance in improving companies' productivity and profitability," International Journal of Production Economics, vol. 105, pp. 70-78, 2007.

[24] U. Al-Turki, "Methodology and theory a framework for strategic planning in maintenance," Journal of Quality in Maintenance Engineering, vol. 17, pp. 150-162, 2011.

[25] O. Chris, Industry Forum, Business Excellence Through Inspired People. "Total Productive Maintenance" [Online]. Available: http://www.industryforum.co.uk/wpcontent/uploads/2011/05/Total-Productive-MaintenanceOverview-Low-Res.pdf

[26] C. K. Mechefske, "Machine Condition Monitoring and Fault Diagnostics," in Vibration an d shock Handbook, C. W. d. Silva, Ed., ed. Boca Raton: CRC press, Taylor and Francis Group, 2005, p. 35 .

[27] R. K. Mobley. (2002, June/2013). An introduction to predictive maintenance (second edition ed.).

W. Whittaker, "Preventing Machine Instalation Problems," U. M. I. Systems, Ed., ed. Jackson, MI, USA: Manufacturing Engineering, 1980, pp. 1-4. 